\title{
Differential Effects of Meloxicam on Pentylenetetrazole- and Maximal Electroshock-Induced Convulsions in Mice
}

\author{
Hadi Darvishi, ${ }^{1}$ Mohsen Rezaei, ${ }^{2}$ Mohammad Javad Khodayar, ${ }^{1,3,}$ Hamid Reza Zargar, ${ }^{1}$ Mohammad \\ Amin Dehghani, ${ }^{1,3}$ Hossein Rajabi Vardanjani, ${ }^{1}$ and Sahebeh Ghanbari ${ }^{1}$ \\ ${ }^{1}$ Department of Toxicology, School of Pharmacy, Ahvaz Jundishapur University of Medical Sciences, Ahvaz, Iran \\ ${ }^{2}$ Faculty of Medical Sciences, Department of Toxicology, Tarbiat Modares University, Tehran, Iran \\ ${ }^{3}$ Toxicology Research Center, Ahvaz Jundishapur University of Medical Sciences, Ahvaz, Iran \\ "Corresponding author: Mohammad Javad Khodayar, Department of Toxicology, School of Pharmacy, Ahvaz Jundishapur University of Medical Sciences, Ahvaz, Iran. Tel: \\ +98-6113738378, E-mail: jkhodayar@yahoo.com
}

Received 2016 January 17; Revised 2016 August 31; Accepted 2016 September 05.

\begin{abstract}
Background: Epilepsy is a group of disorders associated with the abnormal electrical activity of different regions of the brain. The use of anticonvulsant drugs is limited because of their low efficacy, side effects, and toxicity. Therefore, research on new drugs for epilepsy is required. Meloxicam is a non-steroidal anti-inflammatory drug with several biological effects, such as antioxidant, neuroprotective, and anti-inflammatory.

Objectives: Earlier studies gave conflicting reports on the effect of cyclooxygenase inhibitors on seizures. Accordingly, this study was designed to evaluate the effects of meloxicam on pentylenetetrazole (PTZ) and maximal electroshock (MES) models of convulsions

Methods: For each model of convulsion, 48 mice were randomly divided into 6 groups of 8 animals. Group I in two models of convulsions were considered as the control group and the intraperitoneally (i.p.) received vehicle (10 mL $/ \mathrm{kg}$ ). Group II in the PTZ model received the reference anticonvulsant drug, diazepam ( $1 \mathrm{mg} / \mathrm{kg}$, i.p.), and group II in the MES model was treated with phenytoin (25 $\mathrm{mg} / \mathrm{kg}$, i.p.). Groups III - VI in two models of convulsions received four different doses of meloxicam (2.5, 5, 10, and $20 \mathrm{mg} / \mathrm{kg}$, i.p.), respectively. Thirty minutes later, convulsion was induced by PTZ ( $85 \mathrm{mg} / \mathrm{kg}$, i.p.) in PTZ model and by using ear-clip electrodes in the MES model of convulsion.

Results: In the PTZ model, meloxicam showed a significant delayed onset of seizures, Straub's tail, and myoclonic seizure. Different doses of meloxicam reduced the mortality of animals in the PTZ model. In the MES model, meloxicam did not change the duration of hindlimb tonic extension and caused the death of animals unlike the PTZ model.

Conclusions: According to the results, meloxicam has differential effects on two PTZ and MES models of seizure. The anticonvulsant and neuroprotective effects of meloxicam on the PTZ model may be mediated by anti-inflammatory and antioxidant properties. In the MES model, meloxicam did not show any beneficial effect and aggravated convulsive behavior. In the PTZ model, prostaglandins could be involved in the induction of convulsion. Conversely, in the MES model, prostaglandins may attenuate the severity of seizure at the basal level and prevent the development of convulsions. Nevertheless, more studies must be conducted to clarify the mechanisms of action of prostaglandins and meloxicam in the two PTZ and MES models of seizure.
\end{abstract}

Keywords: Meloxicam, Pentylenetetrazole, Maximal Electroshock, Convulsions, Mice

\section{Background}

Epilepsy is one of the major neurological disorders in humans, and it involves about $0.5-1.0 \%$ of the population in the world (1). Inflammatory reactions occur in the brain in various central nervous system (CNS) disorders, including neurodegenerative, autoimmune, and epileptic diseases. Anti-inflammatory and pro-inflammatory cytokines and related molecules have been shown in the plasma and CNS of clinical epileptic cases and experimental models of seizures (2). Evidence shows that the roles of inflammation in the initiation of seizures and epileptogenesis are as follows: a) seizures and status epilepticus induce the production of pro-inflammatory cytokines and inflammatory mediators, b) systemic inflammation can affect the integrity of the blood-brain barrier (BBB), enhance the excitability of neurons, and decrease the seizure threshold, c) disruption of the BBB by inflammatory processes may induce epileptogenesis through the disturbance of brain homeostasis, and d) several anti-inflammatory drugs have been reported to exert antiepileptic actions (2-7). Cyclooxygenases (COXs), the key enzymes that convert arachidonic acid to prostaglandins (PGs), have been implicated in physiological and pathophysiological functions in the CNS. Non-steroidal anti-inflammatory drugs (NSAIDs) known as 
COX inhibitors are commonly used for treating fever and pain state and for the prevention of and therapeutics of many diseases. However, the role of PGs and NSAIDs in the seizure activity is controversial (8). Cyclooxygenase2 (COX-2) activity produces oxidative stress and results in the production of PGs, which have many destructive effects. The transcription of COX-2 has been reported to be induced by synaptic activity and that COX-2 could play a significant role in the pathogenesis of epilepsy (9). Meloxicam is a U.S. food and drug administration-approved drug for rheumatoid arthritis and osteoarthritis (10). Meloxicam is derived from enolic acid and is a potent inhibitor of PG biosynthesis under inflammatory conditions with preferential COX2 inhibitory activity. Prostanoid release in the brain was shown to have been reduced by $20 \%-30 \%$ by meloxicam $(11,12)$. The drug has shown to cause improved gastric and renal tolerability and higher therapeutic index both experimentally and clinically than conventional NSAIDs (10). Moreover, the potential antioxidant activity of meloxicam was found $(13,14)$. Meloxicam attenuated oxidative stress probably by alleviating lipid peroxidation and improving the antioxidant defense system (15). However, this study aimed to investigate the effects of meloxicam on PTZ and MES-induced seizures in mice.

\section{Methods}

\subsection{Experimental Animals}

Male C57 albino mice born and reared in the research center and experimental animal house at the Ahvaz Jundishapur University of Medical Sciences were used in the present study. Young healthy male mice weighing between $24 \mathrm{~g}$ and $28 \mathrm{~g}$ were housed and maintained at a temperature $\left(23 \pm 2{ }^{\circ} \mathrm{C}\right.$ )- and humidity (50 $\left.\pm 10 \%\right)$ - controlled environment under a 12 hours light/dark cycle with alternating food and water, except for a short time when they were removed from their cages for testing. To minimize circadian changes and inter-group variations, all the experiments were conducted between 08:00 a.m. and 14:00 p.m.. Animal testing was carried out in accordance with the institutional guidelines for animal care and use, and all possible measures were taken to minimize the number of animals used. Animals were acclimatized to the new conditions for at least 1 hour before testing.

\subsection{Drugs, Chemicals, and Solutions}

The following drugs were used in the present study: meloxicam (Iran-Hormun, Iran), PTZ (Sigma-Aldrich, USA), phenytoin (HIDANTIC, Caspian Tamin, Iran), and diazepam (ZEPADIC, Caspian Tamin, Iran). All chemicals were dissolved in $0.9 \%$ saline except meloxicam, which was suspended in normal saline containing $0.025 \%$ Tween-80.
Drug solutions were prepared fresh, and the selected doses were administered in $10 \mathrm{ml} / \mathrm{kg}$ animal body weight. The doses of meloxicam were selected on the basis of previous studies on mice and our preliminary observations (16).

\subsection{Pentylenetetrazole-Induced Seizures Test}

Mice were divided into six groups each containing eight animals: vehicle (group I), diazepam (group II) at a dose of $1 \mathrm{mg} / \mathrm{kg}$, i.p., and groups III-VI meloxicam (2.5, 5, 10 , and $20 \mathrm{mg} / \mathrm{kg}$, i.p.), respectively. Thirty minutes later, seizures were induced by the PTZ ( $85 \mathrm{mg} / \mathrm{kg}$, i.p.). The animals were observed during the first $30 \mathrm{~min}$ to evaluate latency for convulsion, Straub's tail, onset of myoclonic seizures, and protection against mortality.

\subsection{Maximal Electroshock(MES)-Induced Seizure Test}

Mice were divided into six groups each containing eight animals and treated with vehicle, phenytoin (25 $\mathrm{mg} / \mathrm{kg}$, i.p.), and meloxicam (2.5, 5, 10 or $20 \mathrm{mg} / \mathrm{kg}$, i.p.), respectively. Thirty minutes later, seizures were induced by a current stimulus ( $50 \mathrm{~mA}, 80 \mathrm{~Hz}$ for 0.2 seconds) delivered using ear electrodes by an electroconvulsometer (Borjsanat Company, Iran). To improve electrode contact, the electrodes were moistened with normal saline before they were attached to the ears of mice $(17,18)$. The current used was predetermined before experimentation. The current that caused hindlimb tonic extension (HLTE) and death did not occur in all mice in the control trials. The duration of HLTE (i.e., the hindlimbs of animals outstretched at $180^{\circ}$ to the plane of the body axis) was recorded. Protection was defined as the complete absence of HLTE.

\subsection{Rotarod Test}

The ataxic behavior of mice was evaluated in the accelerating rotarod test. Mice were placed with the four paws on a $6 \mathrm{~cm}$ diameter rod revolving at $12 \mathrm{rpm}$ exactly $25 \mathrm{~cm}$ above the floor. Mice were trained to remain on the rod for three consecutive trials of 1 minute each. On the next day, all animals in a group received either vehicle, diazepam (1 $\mathrm{mg} / \mathrm{kg}$ ), phenytoin (25 mg/kg, i.p.), or meloxicam. After 30 minutes, each animal was placed on the rod for 1 minute to confirm the absence of any motor coordination disorder.

\subsection{Statistical Analysis}

All the results were presented as mean \pm SEM. Latency to induce convulsive behavior by the PTZ and MES was analyzed by one-way analysis of variance (ANOVA) followed by post hoc Tukey's test for comparison. P values less than 0.05 were considered significant. 


\section{Results}

\subsection{Effect of Meloxicam on PTZ-Induced Seizures}

In PTZ-induced seizures, the administration of meloxicam at doses of 5 and $10 \mathrm{mg} / \mathrm{kg}$ increased the latency for convulsion, Straub's tail, and myoclonic seizure compared with the vehicle $(\mathrm{P}<0.05)$. Meloxicam and diazepam showed significant protection against mortality induced by seizures. Diazepam ( $1 \mathrm{mg} / \mathrm{kg}$, i.p.)-treated animals did not show any signs of convulsions and protected all the mice from PTZ-induced convulsions (Table 1).

\subsection{Effect of Meloxicam on MES-Induced Seizures}

In the MES model, phenytoin prevented the occurrence of HLTE in mice, and meloxicam at any dose did not change the duration of HLTE compared with the untreated control group. Furthermore, meloxicam at all applied doses worsened the condition of mice and caused their mortality (Table 2).

\subsection{Rotarod Test}

Treatment with meloxicam, diazepam (1 mg/kg), and phenytoin (25 mg/kg, i.p.) did not in [U+FB02] uence mice performance in the rotarod test. The effects of these treatments did not alter motor coordination.

\section{Discussion}

In this study, we applied the differential effects of meloxicam on PTZ- and MES-induced convulsions in mice. Meloxicam can be effective in the type of seizure in the PTZ model. The lowest mortality and reduction in duration of myoclonic seizures was obtained at $10 \mathrm{mg} / \mathrm{kg}$. Thus, this dose is considered the most neuroprotective dose in PTZinduced seizures in mice. Meloxicam at a high dose (20 $\mathrm{mg} / \mathrm{kg}$ ) decreased latency to convulsive behavior and increased mortality rate (decrease in mortality protection). Thus, the meloxicam effects at a dose of $20 \mathrm{mg} / \mathrm{kg}$ were reversed. Clinically effective drugs against PTZ-induced seizure can be used in the treatment of myoclonic and absence epilepsy (19-21). Accordingly, meloxicam can be effective in absence epilepsy. As a convulsive agent, PTZ inhibits $G_{A B A_{A}}$ receptors. Therefore, drugs that are agonists at the $\mathrm{GABA}_{\mathrm{A}}$ site can prevent PTZ-induced seizures. Free radicals aggravate epilepsy by increasing the activity of glutamine synthase (22). One of the most common causes of seizures in humans and animals is decreased GABAergic activity and increased glutaminergic system activity. $\mathrm{GABA}_{\mathrm{A}}$ receptors are ligand-gated chloride channels that mediate the inhibitory transmission in the synapses.
The $\mathrm{GABA}_{\mathrm{A}}$ receptor function not only prevents the development of epilepsy but also inhibits the development of convulsive activity throughout the cerebral cortex tissues (23). In many reports, COX-2 is involved in some neurological disorders, such as Alzheimer's disease (24), traumatic brain injury (25), cerebral ischemia (26), and epilepsy (2). Evidence shows that the effect of COX inhibition on seizure activity is highly dependent on many factors, including the nature of the COX inhibitor used (i.e., selective or nonselective) and the experimental model(27). The contribution of COX isoenzymes in the progression and severity of convulsions remains controversial (27). The up-regulation of COX enzyme was shown to occur exclusively in COX-2 isoform following seizure activity (28). COX induction leads to the increase in PGs levels, particularly PGE2, which may facilitate glutamate release from the nerve terminal. This result clarifies the modulator effects of COX inhibitors on glutamate and GABAergic transmission (29). The role of PGs in seizures is known as the PGE2 and PGD2 levels become elevated following PTZ administration (30). Thus, COX inhibitors can be concluded to reduce seizures by inhibiting PG synthesis. Another study showed that meloxicam significantly reduced the increase in brain myeloperoxidase and malondialdehyde levels and restored the glutathione content of the brain (31). COX activation also leads to increased free radical production, which causes oxidative stress, continued apoptosis of GABAergic neurons, and consequently increased glutamate-mediated epileptic discharges (1). COX-2 inhibition up-regulates the expression of $\mathrm{GABA}_{\mathrm{A}}$ receptors, the main fast inhibitory neurotransmitters in the brain; thus, COX-2 inhibitors decrease neuronal excitability and prevent epileptic seizure (9). However, some results of previous studies on the role of COX2 in convulsions are controversial. Pre-treatment with COX-2 inhibitors, such as nimesulide, celecoxib, and indomethacin, is known to aggravate kainic acid-induced seizure activity (32). In the current study, meloxicam did not change the duration time of HLTE and surprisingly caused mortality in animals receiving meloxicam. Consistent with our finding, one study indicated that COX inhibitors were ineffective against MES-induced convulsions (33). By contrast, another study on celecoxib, a selective COX-2 inhibitor, showed that celecoxib had beneficial effects when given in combination with phenytoin against electroshock-induced convulsions (34). According to the results of the current study (Figure 1), meloxicam did not have a neuroprotective effect on the MES model of convulsion. As the administration of meloxicam leads to the decreased basal brain level of PGs, the occurrence of death in the MES model of convulsion in animals receiving meloxicam can represent the basal inhibitory effect of PGs during induction and development of convulsion in mice. How- 
Table 1. Effects of Meloxicam on Pentylenetetrazole-Induced Seizures in Mice ${ }^{\mathrm{a}, \mathrm{b}}$

\begin{tabular}{|c|c|c|c|c|c|c|}
\hline Treatment & Dose, mg/kg & No. & Latency for Convulsion, $s$ & Latency for Straub's Tail, s & Latency for Myoclonic, $s$ & Protection of Mortality, \% \\
\hline Vehicle & $10 \mathrm{~mL} / \mathrm{kg}$ & 8 & $45.25 \pm 2.54$ & $53.25 \pm 2.20$ & $65.5 \pm 2.75$ & 0 \\
\hline Diazepam & 1 & 8 & $228.3 \pm 10.4^{* * *}$ & $1200 \pm 0.0$ & $1200 \pm 0.0$ & $100 \%$ \\
\hline Meloxicam & 2.5 & 8 & $52.625 \pm 1.90$ & $61.25 \pm 2.49$ & $70.875 \pm 3.60$ & $50 \%$ \\
\hline Meloxicam & 5 & 8 & $60.625 \pm 2.64^{*}$ & $68.75 \pm 1.64^{*}$ & $79.5 \pm 3.73^{*}$ & $62.5 \%$ \\
\hline Meloxicam & 10 & 8 & $75.5 \pm 3.32^{*}$ & $84.625 \pm 2.87^{*}$ & $107.375 \pm 4.11^{*}$ & $75 \%$ \\
\hline Meloxicam & 20 & 8 & $51.625 \pm 2.02$ & $56.5 \pm 1.34$ & $63.75 \pm 1.82$ & $12.5 \%$ \\
\hline
\end{tabular}

${ }^{\mathrm{a}}$ Values are expressed as mean \pm SEM.

${ }^{\mathrm{b}}$ Data were analyzed by one-way ANOVA followed by Tukey's HSD multiple comparison test, ${ }^{*} \mathrm{P}<0.05,{ }^{* * *} \mathrm{P}<0.001$ compared with the vehicle group.

Table 2. Effects of Meloxicam on Maximal Electroshock-Induced Seizures in Mice

\begin{tabular}{lcccc}
\hline Treatment & Dose, $\mathbf{m g} / \mathbf{k g}$ & No. & Hindlimb Tonic Extensions, s & Mortality, \% \\
\hline Vehicle & $10, \mathrm{~mL} / \mathrm{kg}$ & 8 & $14.62 \pm 0.59$ \\
Phenytoin & 25 & 8 & $0.0 \pm 0.0$ & 0 \\
Meloxicam & 2.5 & 8 & $16.5 \pm 0.45$ & $14 \pm 0.53$ \\
Meloxicam & 5 & 8 & $16.5 \pm 0.56$ \\
\hline Meloxicam & 10 & 8 & $16 \pm 0.59$ \\
\hline Meloxicam & 20 & 8 & $25 \%$ \\
\hline
\end{tabular}

ever, meloxicam in the PTZ model showed a significant anticonvulsive activity. This result indicates that PGs contribute to the induction of convulsions in the PTZ model. However, future studies are required to clarify the effect of NSAIDs on and the role of PGs in the induction and development of convulsion in different models of seizures.

\section{Acknowledgments}

We would like to thank the toxicology research center and the deputy of research affairs of Ahvaz Jundishapur University of Medical Sciences.

\section{Footnotes}

Authors' Contribution: Study concept, design, drafting, and revision of the manuscript, Mohammad Javad Khodayar; Mohsen Rezaei and Hadi Darvishi; testing procedures, statistical analysis, and interpretation of data, Mohammad Javad Khodayar, Hamid Zargar; Mohammad Amin Dehghani, Hossein Rajabi Vardanjani and Sahebeh Ghanbari. This article is the Pharm. D. doctoral thesis of Hadi Darvishi.

Funding/Support: This study was supported by a grant from the toxicology research center of Jundishapur Uni- versity of Medical Sciences under the deputy of research affairs of Ahvaz Jundishapur University of Medical Sciences. 


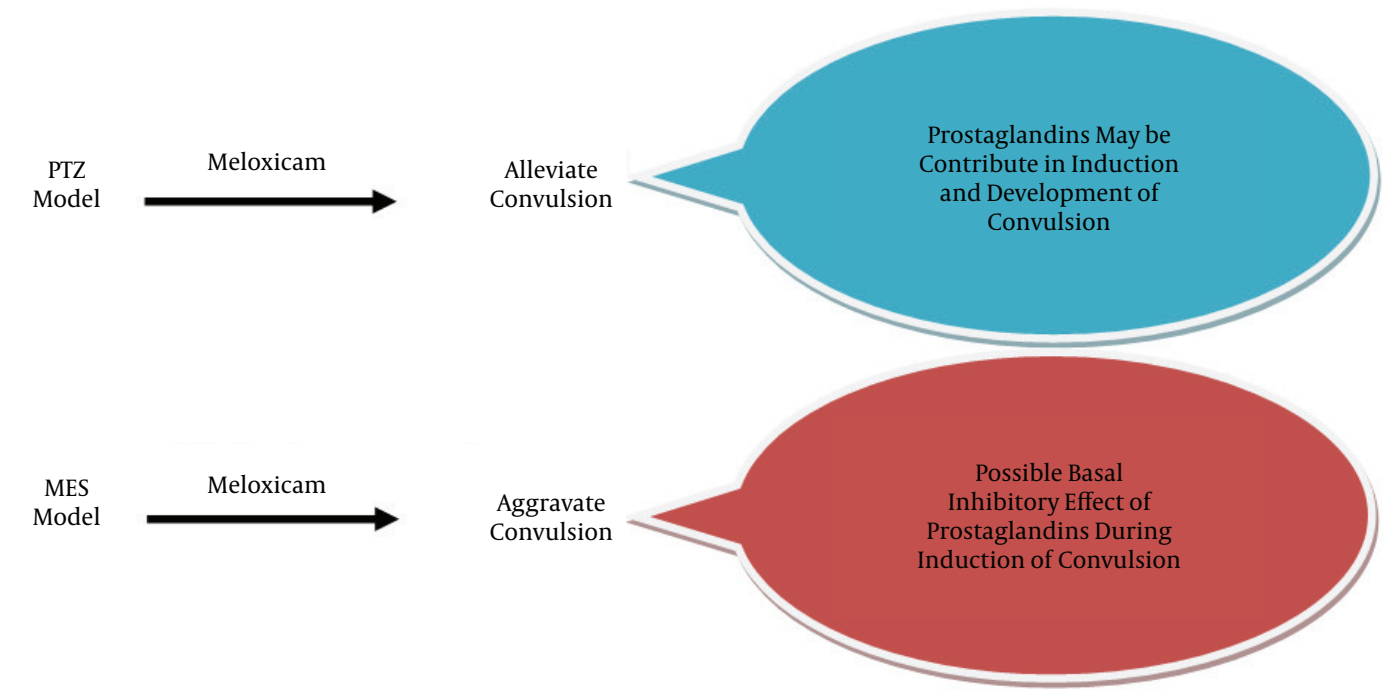

Figure 1. Schematic of the Possible role of Meloxicam in Both PTZ and MES Models of Convulsions.

\section{References}

1. Dhir A, Naidu PS, Kulkarni SK. Effect of naproxen, a non-selective cyclo-oxygenase inhibitor, on pentylenetetrazol-induced kindling in mice. Clin Exp Pharmacol Physiol. 2005;32(7):574-84. doi: 10.1111/j.14401681.2005.04233.x. [PubMed: 16026518].

2. Vezzani A, Granata T. Brain inflammation in epilepsy: experimental and clinical evidence. Epilepsia. 2005;46(11):1724-43. doi: 10.1111/j.15281167.2005.00298.x. [PubMed: 16302852].

3. Vezzani A, Balosso S, Ravizza T. The role of cytokines in the pathophysiology of epilepsy. Brain Behav Immun. 2008;22(6):797-803. doi: 10.1016/j.bbi.2008.03.009. [PubMed: 18495419].

4. Vezzani A, Baram TZ. New roles for interleukin-1 Beta in the mechanisms of epilepsy. Epilepsy Curr. 2007;7(2):45-50. doi: 10.1111/j.15357511.2007.00165.x. [PubMed: 17505552].

5. Choi J, Koh S. Role of brain inflammation in epileptogenesis. Yonsei Med J. 2008;49(1):1-18. doi: 10.3349/ymj.2008.49.1.1. [PubMed: 18306464].

6. Takemiya T, Matsumura K, Yamagata K. Roles of prostaglandin synthesis in excitotoxic brain diseases. Neurochem Int. 2007;51(2-4):112-20. doi:10.1016/j.neuint.2007.05.009. [PubMed:17629358].

7. Rijkers K, Majoie HJ, Hoogland G, Kenis G, De Baets M, Vles JS. The role of interleukin-1 in seizures and epilepsy: a critical review. Exp Neurol. 2009;216(2):258-71. doi: 10.1016/j.expneurol.2008.12.014. [PubMed: 19162013].

8. Mirhadi K. Anticonvulsant effect of celecoxib in mice induced by PTZ. Middle-East J Sci Res. 2012;11(3):272-8.

9. Haiju Z, Ruopeng S, Gefei L, Lu Y, Chunxi L. Cyclooxygenase-2 inhibitor inhibits the hippocampal synaptic reorganization by inhibiting MAPK/ERK activity and modulating GABAergic transmission in pilocarpine-induced status epilepticus rats. Med Chem Res. 2008;18(2):71-90. doi: 10.1007/s00044-008-9109-0.

10. Gates BJ, Nguyen TT, Setter SM, Davies NM. Meloxicam: a reappraisal of pharmacokinetics, efficacy and safety. 2005

11. Tegeder I, Neupert W, Guhring H, Geisslinger G. Effects of selective and unselective cyclooxygenase inhibitors on prostanoid release from various rat organs. J Pharmacol Exp Ther. 2000;292(3):1161-8. [PubMed: 10688636].
12. Engelhardt G, Bögel R, Schnitzler C, Utzmann R. Meloxican: Influence on arachidonic acid metabolism. Biochem Pharmacol. 1996;51(1):2938. doi:10.1016/0006-2952(95)02110-8.

13. Kalonia H, Kumar A. Suppressing inflammatory cascade by cyclooxygenase inhibitors attenuates quinolinic acid induced Huntington's disease-like alterations in rats. Life Sci. 2011;88(17-18):784-91. doi: 10.1016/j.lfs.2011.02.020. [PubMed: 21362433].

14. Edfawy M, Hassan MH, Mansour A, Hamed AA, Amin HA. Meloxicam modulates oxidative stress status, inhibits prostaglandin E2, and abrogates apoptosis in carbon tetrachloride-induced rat hepatic injury. Int JToxicol. 2012;31(3):276-86. doi: 10.1177/1091581812442939. [PubMed: 22556387].

15. Gurocak S, Ure I, Cumaoglu A, Gonul I, Sen I, Tan O, et al. Renal tissue damage after experimental pyelonephritis: role of antioxidants and selective cyclooxygenase-2 inhibitors. Urol. 2010;76(2):1-5.

16. Roughan JV, Wright-Williams SL, Flecknell PA. Automated analysis of postoperative behaviour: assessment of HomeCageScan as a novel method to rapidly identify pain and analgesic effects in mice. Lab Anim. 2009;43(1):17-26. doi: 10.1258/la.2008.007156. [PubMed: 19015177].

17. Sayyah M, Mandgary A, Kamalinejad M. Evaluation of the anticonvulsant activity of the seed acetone extract of Ferula gummosa Boiss. against seizures induced by pentylenetetrazole and electroconvulsive shock in mice. J Ethnopharmacol. 2002;82(2-3):105-9. doi: 10.1016/s0378-8741(02)00166-6.

18. Luszczki JJ, Glowniak K, Czuczwar SJ. Time-course and dose-response relationships of imperatorin in the mouse maximal electroshock seizure threshold model. Neurosci Res. 2007;59(1):18-22. doi: 10.1016/j.neures.2007.05.004. [PubMed: 17602770].

19. Peterson SL. Glycine potentiation of anticonvulsant drugs in pentylenetetrazol seizures in rats. Brain Res Bull. 1991;26(1):43-7. [PubMed: 2015517].

20. Loscher W, Honack D, Fassbender CP, Nolting B. The role of technical, biological and pharmacological factors in the laboratory evaluation of anticonvulsant drugs. III. Pentylenetetrazole seizure models. Epilepsy Res. 1991;8(3):171-89. [PubMed: 1907909].

21. Namvaran A, Tavakkoli G. The effect of Salvia officinalis hydroalcoholic extract on PTZ-induced seizure threshold in Vincristine injected mice. 2012 
22. Oliver CN, Starke-Reed PE, Stadtman ER, Liu GJ, Carney JM, Floyd RA. Oxidative damage to brain proteins, loss of glutamine synthetase activity, and production of free radicals during ischemia/reperfusion-induced injury to gerbil brain. Proc Natl Acad Sci U S A. 1990;87(13):5144-7. [PubMed: 1973301].

23. Abbasnejad M, Keramat B, Mahani E, Rezaeezade-Roukerd M. Effect of hydro-methanolic extract of sour orange flowers, Citrus aurantium, on pentylentetrazole induced seizure in male rats. J Babol Univ Med S. 2012;14(5):20-8.

24. Melnikova T, Savonenko A, Wang Q, Liang X, Hand T, Wu L, et al. Cycloxygenase-2 activity promotes cognitive deficits but not increased amyloid burden in a model of Alzheimer's disease in a sex-dimorphic pattern. Neuroscience. 2006;141(3):1149-62. doi: 10.1016/j.neuroscience.2006.05.001. [PubMed: 16753269].

25. Cernak I, O'Connor C, Vink R. Activation of cyclo-oxygenase-2 contributes to motor and cognitive dysfunction following diffuse traumatic brain injury in rats. Clin Exp Pharmacol Physiol. 2001;28(11):9225. [PubMed: 11703397].

26. Nakayama M, Uchimura K, Zhu RL, Nagayama T, Rose ME, Stetler RA et al. Cyclooxygenase-2 inhibition prevents delayed death of CA1 hippocampal neurons following global ischemia. Proc Natl Acad Sci U S A. 1998;95(18):10954-9. [PubMed: 9724811].

27. Katyal J, Kumar H, Gupta YK. Anticonvulsant activity of the cyclooxygenase-2 (COX-2) inhibitor etoricoxib in pentylenetetrazolekindled rats is associated with memory impairment. Epilepsy Behav. 2015;44:98-103. doi: 10.1016/j.yebeh.2014.12.032. [PubMed: 25660085].

28. Takemiya T, Suzuki K, Sugiura H, Yasuda S, Yamagata K, Kawakami Y, et al. Inducible brain COX-2 facilitates the recurrence of hippocampal seizures in mouse rapid kindling. Prostaglandins Other Lipid Mediat.
2003;71(3-4):205-16. [PubMed: 14518562].

29. Dhir A, Kulkarni SK. Rofecoxib, a selective cyclooxygenase-2 (COX-2) inhibitor potentiates the anticonvulsant activity of tiagabine against pentylenetetrazol-induced convulsions in mice. Inflammopharmacology. 2006;14(5-6):222-5. doi: 10.1007/s10787-006-1535-3. [PubMed: 17139446].

30. Wallenstein MC, Mauss EA. Effect of prostaglandin synthetase in hibitors on experimentally induced convulsions in rats. Pharmacology. 1984;29(2):85-93. [PubMed: 6433367].

31. Hakan T, Toklu HZ, Biber N, Ozevren H, Solakoglu S, Demirturk $\mathrm{P}$, et al. Effect of COX-2 inhibitor meloxicam against traumatic brain injury-induced biochemical, histopathological changes and blood-brain barrier permeability. Neurol Res. 2010;32(6):629-35. doi: 10.1179/016164109X12464612122731. [PubMed: 19660237].

32. Kim HJ, Chung JI, Lee SH, Jung YS, Moon $\mathrm{CH}$, Baik EJ. Involvement of endogenous prostaglandin F2alpha on kainic acid-induced seizure activity through FP receptor: the mechanism of proconvulsant effects of COX-2 inhibitors. Brain Res. 2008;1193:153-61. doi: 10.1016/j.brainres.2007.12.017. [PubMed: 18178179].

33. Dhir A, Naidu PS, Kulkarni SK. Effect of cyclooxygenase-2 (COX-2) inhibitors in various animal models (bicuculline, picrotoxin, maximal electroshock-induced convulsions) of epilepsy with possible mechanism of action. Indian J Exp Biol. 2006;44(4):286-91. [PubMed: 16629370].

34. Dhir A, Naidu PS, Kulkarni SK. Neuroprotective effect of nimesulide, a preferential COX-2 inhibitor, against pentylenetetrazol(PTZ)-induced chemical kindling and associated biochemical parameters in mice. Seizure. 2007;16(8):691-7. doi:10.1016/j.seizure.2007.05.016. [PubMed: 17604186]. 